\title{
The Industry Commission and the Community Sector
}

\author{
Mark Lyons
}

$\mathrm{T}$

The 1993 revision of the System of National Accounts has identified nonprofit institutions as a distinct institutional unit and nonprofit institutions serving households as a distinct sector (Inter-Secretariat Working Group on National Accounts, 1993). This reflects the increasing worldwide recognition of this class of organisation (Salamon, 1994). Yet little interest in them has been evident in Australia, even though nonprofit organisations have attracted a good deal of attention overseas, including from university economists in the United States (Rose-Ackerman, 1986; Weisbrod, 1988; Ben-Ner \& Gui, 1993). Nonprofit organisations are less visible in Australia than in the United States, though one estimate suggests that as a percentage of private employment, nonprofit employment in Australia is almost as large as that in the United States (Lyons, 1994). But the low profile of Australia's nonprofits may be about to change.

In September 1992, in an unusual move, the Treasurer included in the forward work plan of the Industry Commission (IC) an inquiry into 'charitable organisations' in Australia. Terms of reference were issued late in 1993 to the Commission, whose draft report, Chanitable Organisations in Australia: An Inquivy into Community Social Welfare Organisations, was published on 27 October 1994. A final report is due to appear at the end of June 1995. The draft report (hereafter 'the report') is a substantial document. It contains a number of important draft recommendations that deserve to be reviewed along with the evidence and reasoning that are used to support them.

The inquiry was presided over by the Chairman of the IC, Bill Scales, assisted by another industry commissioner, Roger Maulden, and an associate commissioner, Sister Margaret McGovern, who had just retired as Director of the Mercy Family Centre in Sydney. The Inquiry received 443 submissions and took evidence from 156 parties. Some research was undertaken by IC staff and by consultants.

The announcement of the inquiry caused considerable unease among those organisations that were to be the object of inquiry. Many believed that the IC would be burdened by the ideological baggage of 'economic rationalism' and would be unable to recognise either the important non-economic contribution of these organisations or their mode of operation. These early fears were misplaced; the report has been gen-

Mark Lyons is Associate Professor in the School of Management, and Director of the Centre for Australian Community Organisations and Management (CACOM), at the University of Technology, Sydney. 
erally welcomed by 'charitable organisations' or the community sector. But two recommendations - those proposing mandatory competitive tendering for government grants and removal of the fringe-benefits tax exemption - have attracted a good deal of critical comment.

\section{Terminology and Terms of Reference}

The terms of reference handed the IC showed that the Treasury had only a vague idea about the organisations in which it was interested. The term 'charitable organisations' was not well chosen as the terms of reference indicated that the Treasury was interested in only some of the organisations recognised by the courts and the Australian Taxation Office (ATO) as charities. In its report, the IC has invented another term, 'community social welfare organisations'; but that invention is little better since many of the organisations covered by the terms of reference resist being called 'welfare organisations', arguing that the term 'welfare' stigmatises them and their clients. The inquiry deals mainly with private, nonprofit organisations in the community services industry and the non-institutional part of the health industry. Most workers in these organisations refer to them as 'community organisations' and as constituting a 'community sector'. That terminology will be used in this article.

The community sector includes organisations like the Smith Family, Spastic Societies or Centres, and the Society of St Vincent de Paul, as well as nonprofit nursing homes, childcare centres, and many thousands of small neighbourhood centres, refuges and advocacy organisations. The report estimates (and probably over-estimates) that more than 10,000 such organisations exist. In 1992/93 they received nearly A $\$ 2.8$ billion in government grants, which was estimated to constitute 57 per cent of their total income. Over 60 per cent of government funding came directly from the Commonwealth. Some community organisations are very large. Data collected by commission staff indicate that the 30 largest had a total annual expenditure of almost $\$ 1.5$ billion and held over $\$ 2.2$ billion in assets. But there are also many thousands of organisations with few assets and an annual expenditure of less than $\$ 500,000$ per year. The commissioners were clearly surprised and impressed by the size of the community sector and by the amount of government revenue that supports it. It is likely that many Australians will share that surprise.

Government regulation of community organisations is confused and/or non existent, and achieves neither accountability nor efficiency. It is to this issue that the IC's report addresses most of its attention. Most organisations have a legal identity as incorporated associations under State and Territory legislation; some are incorporated as companies limited by guarantee and are therefore supervised by the Australian Securities Commission (ASC). Some are established by statute, while many are unincorporated but sponsored by churches or religious orders. Fund-raising is regulated in most States and Territories but by means of a hotch-potch of sometimes contradictory rules that contain many exemptions. Taxation legislation provides many concessions to different sets of nonprofit organisations; but the ATO provides only a limited scrutiny and Treasury cannot provide even the roughest estimates of what these concessions might cost. By contrast, government funding programs often require very de- 
tailed reporting of expenditure and client data, giving rise to the charge of overregulation. There is little uniformity in reporting requirements and only rarely does a government grant ever purport to cover the cost of providing a service.

The report makes a number of recommendations designed to improve the accountability and efficiency of community organisations and to place relations between governments and the community sector on a more professional footing. It should be noted that the IC was not invited, and so did not attempt, to describe an ideal model for allocating tasks and responsibilities between the government and community sector. Rather, it sought to address the current rather messy set of relations and to suggest relatively modest reforms that would improve those relations and produce better outcomes for the many Australians who receive government subsidised services from community organisations.

Essentially, the report proposes that when a government wants a service provided it should contract with community organisations (or with for-profits if they are interested) after a process of competitive tendering. Congruent with this, it proposes that the level of reporting to government program managers be reduced, while organisational accountability to the wider public be strengthened, by bringing all of the larger community organisations under the scrutiny of the ASC. It recognises that community organisations are qualitatively different from for-profit organisations and recommends that they retain some of their existing favourable tax treatment. Yet, although the overall thrust of the report seems reasonably clear, its recommendations are not entirely consistent and its arguments are not convincing in every respect.

\section{Efficiency and Order through Contracting}

Government grants have always provided much of the community sector's revenue. But until the 1970s, most government grants were provided to assist the 'good work' being carried out by community organisations. Despite the growth in government funding since the late 1960s, many grants still appear to be paid on that basis. That is to say, a government department does not presume to pay the full cost to the organisation of providing a service. It presumes that the organisation will find revenue from other sources: from user fees (but often the government will cap or prohibit these); from its fund-raising efforts; or from investments and other business ventures. Yet governments take the credit for providing these services and seek to control them as if they were fully funding them. This anomaly is a major complaint of community organisations.

The report appears to acknowledge the validity of this complaint and recommends that funding agreements should take into account the full cost of providing a service, including organisational overheads, staff training and research and development (Draft Recommendation [DR]2). Although the report does not do so, one may view the government as the sole purchaser of many of the services provided by community organisations, and its failure to pay the full cost of these services as an abuse of its monopsony power. If governments insist that they are simply contributing to the costs of providing a needed service, then they should adopt a far more cooperative approach to services planning than is currently the case. 
The report recommends that these payments should be made for defined outputs. 'Output funding' is a piece of jargon currently popular with public servants in some States, but it is not easily applied to the provision of community services. 'Outputs' endorsed by the report include hours of nursing care (p.282), which some might consider better described as an input. Indeed, the report considers them as precisely that two pages earlier. The report sensibly eschews an approach to funding whereby a government department identifies sets of inputs, such as certain staff salaries and vehicle costs. However, it would also be sensible to acknowledge more clearly the difficulty of defining outputs. It should also encourage governments to conduct more extensive dialogue with providers, so as to define jointly the outputs that might then become the basis of funding agreements. By and large, government officials are not experienced in the provision of most community services.

The report proposes that governments should select service providers by open tender (DR4). This recommendation is central to the report's overall approach. Its authors appear to believe that if all or most government support for the work of community organisations were organised within the well established rules and practices of tendering and contracting, the relations between the two sectors would become more professional. Yet the recommendation has been widely criticised by the community sector. Competitive tendering is already used in a few government programs, but to propose it apparently as the sole method whereby governments should support community organisations (and any for-profits that wish to tender) is somewhat extreme. It may make sense for the provision of clearly identifiable services such as childcare, hostel accommodation or home nursing, but it is hard to see how it could work in the case of less easily defined but arguably just as important services as youth work or community development.

Criticism of this draft recommendation takes two forms. Many community organisations claim they undertake community development as part of providing other services. They fear that an exclusive focus on more conventional and tangible services would preclude government support for that other kind of work. The claim that community organisations develop communities while providing other services has never been thoroughly demonstrated; but the report ignores the claim and so dodges the argument. The report does sensibly recognise that competitive tendering will not work in all cases. A clearer acknowledgment of this in the recommendation would help ease some of the disquiet.

The recommendation causes unease also because it appears to preclude community organisations from any role in the planning of government funded services. It appears to repudiate the partnership that many in the community sector would like to have with government. (The report notes that the term 'partnership' was rarely employed by government officials.) The recommendation enforces competition between community organisations, whereas many in the community sector claim to be seeking cooperation and collaboration, at least in service provision, both with government and among themselves. Critics are probably reading too much into this recommendation, but they are correct to detect a tension in the report between wanting to create truly competitive markets for services and supporting some of the more recent manage- 
ment techniques that recognise that collaboration and cooperation between purchasers and providers is more likely to guarantee quality than the threat of competition. An interchange at the IC hearings between Bill Scales and two senior officials of the Health and Community Services Department in Victoria is interesting in this connection. The Victorian government over the past two or three years has embraced competitive tendering for community services more enthusiastically than any other Australian government. The two officials argued strongly that the way to produce efficiency and quality in community organisations was to threaten them every few years with the cessation of government support. Scales, equally strongly, reminded them that that approach was counter to best practice in the business sector where large firms sought to develop supportive relationships with their suppliers (IC, 1994:2997-8).

Other contradictions abound in the report's treatment of competitive tendering. The report is not entirely clear on the point, but generally it seems to favour fixedprice tendering rather than price-competitive tendering, on the grounds that this would enable governments to choose on the basis of service quality. But two pages further on (p.292) the report speculates that organisations might be prepared to subsidise their bids for government contracts. This would seem more likely to happen if tendering were competitive by price, unless governments used their monopsony power to set the price at below cost, effectively forcing the provider organisation to subsidise those services apparently funded by government (as happens now). This might please Treasury officials but it would mean that community organisations were subsidising those services from their own resources, thus reducing their capacity to meet the need for services that governments do not subsidise. Those members of the public who donate over half a billion dollars annually to community organisations might not be pleased to know that most of their donations are going to support services that governments claim to be funding.

This section of the report directly contradicts the draft recommendation that governments should pay the full cost of providing the services it contracts. To remove the potential for abuse of monopsony power by government, some form of independent community-services pricing tribunal might be sensible. This could work in a similar way to pricing tribunals set up to guard against abuse of monopoly power by recently corporatised government trading enterprises.

As an alternative to contracting, the government could fully or partly pay for the services it desires for particular population groups by means of a voucher or quasivoucher system. Under such a system, the government effectively agrees to meet the cost of or a certain portion of the costs of specified users of services. Under these arrangements, rather than government purchasing a group of services on behalf of service users, the users themselves, or their families, choose a particular service whose providers then bill the government for a predetermined amount. In theory, at least, such a method is more likely to ensure a consumer focus from the service provider than the tendering model, in which the provider has to convince a government official that the services on offer are of appropriate quality and meet consumers needs. During the late 1980s, the Commonwealth Department of Human Services and Health (to use its current title) developed quasi-voucher types of arrangements for many of its 
major programs (Lyons, 1995). But changes at the top in that department and the handing of certain programs to the States dissipated the impetus behind these developments. Unfortunately, the IC also forwent the opportunity to explore this experience of vouchers, although it has indicated it would like further submissions on the matter.

\section{Improving Accountability}

The report acknowledges that the plethora of different reporting requirements imposed by each government program is not only inefficient but does nothing to make the recipient organisations accountable to the public, which not only provides tax revenue for the government to pass on as grants but also provides resources to most organisations directly by way of donations of money and time. Other regulatory authorities also fail to ensure the public accountability of community, indeed of all nonprofit, organisations. These include the ATO and the various State government authorities which provide many organisations with a legal identity as incorporated associations, and which regulate fundraising. The broad direction of reform favoured by the report is to reduce as far as possible the program-specific reporting requirements while at the same time introducing mechanisms for ensuring greater accountability to the wider public for both the operation of the organisation and for the quality of their services. In this context DR21, proposing the development of specific accounting standards for community organisations (read all nonprofits), is important. It will be only after the establishment of such standards that financial reports from community organisations will be readily understood and capable of being compared.

This lack of transparent public accountability of nonprofits in Australia contrasts with the experience of comparable overseas countries. In the United States and Canada, all but the smallest tax-exempt organisations must file annual returns. These are public documents and can be accessed by any member of the public. In Australia, the ATO does not even possess a single list of organisations that can give tax deductibility to their donors. The lists they do possess are not public documents. Tax-exempt organisations are asked not to file tax returns. In Britain, details of those nonprofit organisations that are charities can be obtained from the Charities Commissioner. Most Australian States and Territories require many organisations that receive funds from the public to register and file details of their fund-raising, but the requirements vary from State to State and are haphazardly enforced. As well, in some States these records are confidential. State and Territory authorities that incorporate nonprofit organisations as associations are poorly resourced and record keeping is patchy; no member of the public could obtain information on an organisation by that route. In the United States, Canada and Britain independent organisations such as the National Charities Information Bureau and the Charities Aid Foundation use publicly available data to complete league tables of nonprofit organisations according to their performance on a number of indicators such as fund-raising efficiency or use of debt. This is impossible in Australia.

The report argues that accountability can be best improved by bringing most community organisations (and, by implication, most nonprofits) under the scrutiny of 
the ASC. At first sight, this seems sensible. In so far as many community organisations seek donations from the public and in so far as they all receive some indirect public support through special tax concessions, they should be accountable to the public in the same way as public companies are. The report therefore proposes that those organisations above a certain size (to be determined) should be incorporated under corporations law, or, if incorporated by own statute, be required to report as if they were (DR20). However, there are several problems with this recommendation. The ASC no doubt has a very efficient and effective compliance system, but it is not clear that it could add to its responsibilities tens of thousands of nonprofit organisations (there are approximately 100,000 incorporated associations Australia-wide, most, but by no means all, small). The requirement to incorporate under corporations law could be restricted to quite large organisations; but then many thousands of organisations would continue to receive little or no scrutiny and to remain as invisible to the public as they are now.

In some of the details of its treatment of accountability the report is less vigorous than it might be. It draws a distinction between government supervision and public scrutiny. Both are presumably necessary components of an adequate system of accountability. It rejects the call, made in some submissions, for a national supervisory authority on the lines of Britain's Charities Commission, claiming that supervision is better provided by existing State and Territory authorities. Yet that supervision, whether of fund-raising or of incorporated associations, is at best patchy, often contradictory between States, and mostly non-existent. All the report proposes is greater intergovernmental cooperation. Yet it does acknowledge that current level of supervision by the ATO of organisations claiming entitlement to the extensive array of tax concessions is inadequate. It proposes a more thoroughgoing review by the ATO (DR19). Oddly, the incorporation of at least large nonprofits as companies limited by guarantee is recommended merely to improve the public availability of information. Yet the ASC would be required to provide supervision as well as collect data. One wonders why these organisations need supervision by State fund-raising authorities as well. A more thoroughgoing overhaul and some culling of existing accountability mechanisms seems called for.

There is no reason to retain State and Territory regulation of fundraising by incorporated nonprofits, so long as the authorities responsible for incorporation can ensure both appropriate supervision of organisations enjoying that status and the public availability of information. This they manifestly cannot do at present. To this end, rather than transferring the supervision of an indeterminate number of incorporated associations to regulation by the ASC, as the report proposes, it seems more sensible to bring all incorporated nonprofits under the supervision of a single national specialist nonprofit commission, which would give the task of regulating the attention it deserves. Such an arrangement, provided it replaced the existing shambles of State and national arrangements and provided it was informed by a belief that scrutiny by the public rather than by public servants is the best guarantee of accountability, would introduce a less onerous reporting regime for nonprofits and a more efficient and effec- 
tive use of public resources. It would also give appropriate recognition to this important class of organisations.

\section{Taxation Issues}

Governments support community organisations and many other nonprofits in an indirect way mainly by exempting them from a number of taxes and allowing donors to deduct the value of their donations from their taxable income. The current set of tax concessions is highly complex and generates of a number of anomalies. It has also attracted some hostility from some for-profit organisations competing with nonprofits.

Income tax. Almost all community organisations - indeed, almost all nonprofit organisations - are exempt from tax on their (net) income. This is more generous treatment than in the United States and many other countries, where income from unrelated business activities is taxed. Australian community organisations have argued that, since profits from their business activities were being applied solely to their main 'charitable' work, they should remain tax-exempt. The report agrees. It accepts that the structure of incentives for the business ventures of community organisations requires them to be price-takers rather than price-makers and that they were unlikely to use their advantage to seek to dominate markets. It also notes how difficult it would be in practice to identify those business ventures that were not part of an organisation's core business. Indeed, most of the complaints from for-profit competitors came from organisations that are competing with what are clearly the core activities of relevant nonprofits, such as hospitals, nursing homes and childcare centres. The report also notes that nonprofits faced some disadvantages when compared with for-profits, such as in raising capital.

Input taxes. Input taxes include sales tax, fringe-benefits tax (FBT), payroll tax, banktransaction taxes, land tax and rates. Only those community organisations that qualify as public benevolent institutions (PBIs) are exempt from all of these taxes, though the full range of exempt organisations varies among the States. The report finds convincing the arguments that these taxes produce unfair competition and allocative inefficiencies (though the evidence and the arguments advanced are at best sketchy). It also finds merit in the argument that government support is better applied directly than in the form of tax concessions, though it rejects this angument in the case of income-tax exemptions and tax deductibility of donations.

The argument that tax exemptions for community organisations produces allocative inefficiencies in industries such as child care and nursing homes, where nonprofits compete directly with for-profits, is, on the surface, self-evidently true. But it is not an argument for removing input-tax concessions from all community organisations that currently enjoy them. Given that the relevant industries are highly regulated and subsidised and that for-profits are clearly not being driven out of business by taxsubsidised nonprofits, it would seem more sensible to examine closely the selective advantages and efficiencies of these two different organisational forms. 
Community organisations that are PBIs - and this includes almost all large community organisations - also point to the 'churning' effect of requiring them to pay such taxes. With government grants providing on average 60 per cent of their income, they argue that it would be foolish to tax them as this would do no more than return part of these grants to the government, though not necessarily to the government that provided the grants. It would thus increase the complexity of the already vexed field of Commonwealth/State financial relations. Some also argue that the knowledge that community organisations are taxed would inhibit donors who are reluctant to see their donations partly siphoned off to the government in tax. The report acknowledges that abolishing input-tax exemptions would cause hardship and proposes that the Council of Australian Governments examine (with one exception) the possibilities of introducing a revenue-neutral package of direct assistance to replace these existing concessions and of standardising criteria for eligibility across jurisdictions (DR9 and DR10).

The exception is the FBT exemption enjoyed by PBIs. The report notes the claims that some PBIs were using this exemption to construct salary packages for senior staff that were almost entirely comprised of fringe benefits. It recommends its removal (DR11). This has aftracted most of the attention of a number of larger community organisations, especially in the disability-services field. They argue that the FBT exemption has allowed them to offer salary packages sufficient to attract highly experienced managers without consuming too great a portion of their limited funds. Other organisations note that some fringe benefits, such as providing accommodation to house parents, are part of their core function and that to be taxed on them simply increases their costs. Disability-service organisations have already imposed a voluntary ceiling of 30 per cent of the use of fringe benefits and it seems likely that the government will impose some such limit rather than abolish the concession altogether.

Tax deductibility of donations. Donors to PBIs may deduct donations from their taxable income. But whereas such tax deductibility is not available to donors to most other community organisations, it is available to donors to a wide range of other organisations, such as public hospitals, universities, school building appeals and to arts, sporting and environment groups. This produces some interesting anomalies. For example, a donation to a yacht club may be tax deductible, while a donation to a neighbourhood centre or a youth group probably will not be. The word 'probably' is used deliberately because another feature of the ATO's administration of tax deductibility is its inconsistency. An organisation providing similar services may be classed as a PBI in one place while a similar organisation elsewhere is not (Lyons, 1993). The IC inquiry also addressed the questions of whether a continuation of tax deductibility was justified given that the government could effect its purpose more precisely by grants, and if so, whether it should continue to operate as a concession or be converted to a tax rebate or tax credit as argued by some Australian tax experts (Krever, 1991).

On the question of whether donations should be tax-deductible at all, the report accepted the weight of evidence from numerous United States studies that it was 
'treasury efficient' (p.230). In effect, this means that the extra donations stimulated by deductibility exceed the tax revenue lost to the government by that provision. Thus, although governments have only limited control over which organisations donations might be directed to, it was an efficient way of encouraging private support for public goods. The report also argues that current arrangements support pluralism by allowing individuals to 'direct government expenditure to the charity of their choice' (p.229). It acknowledges, but does not endorse, the argument that a donation is not part of a person's taxable income and therefore exempting it from taxation does not create a tax expenditure (p.223). The report does not touch on the question of changing the tax concession to a tax rebate.

The report accepts that the current arrangement favouring PBIs creates an inconsistency in government support for community organisations in that court interpretations of what constitutes a PBI stress that such an organisation must give identifiable relief to an identifiably disadvantaged person. Organisations that primarily tackle poverty and disadvantage by preventive techniques such as counselling, education, advocacy and community development are for the most part excluded. Yet these techniques are also used by large community organisations that have PBI status by virtue of their more traditional 'charitable' activities. The report recommends that, in the interests of consistency, tax deductibility of donations should be extended to all community organisations (DR6).

The intention is clear. But the proposal illustrates why a body staffed by economists could benefit occasionally from legal advice. The report argues that all organisations encompassed by its terms of reference, organisations it calls 'Community Social Welfare Organisations', should be able to give tax deductibility to their donors. Yet that term is nowhere clearly defined. The context suggests that the IC uses the term to refer to organisations that are granted charitable status under two of the four conventional heads of charity: relief of poverty and other public benefit (the other two heads are advancement of education and advancement of religion). The problem with this approach, as has recently been argued (McGregor-Lowndes, 1994), is that it includes many other organisations that the IC presumably would not want included, such as funds for the beautification of townships, or the erection of bridges or to assist the poor relatives of a wealthy entrepreneur. These anomalies arise because charity law is exclusively case law, and over the past 400 years courts have allowed as charities arrangements which seem incongruous in the late 20 th century, but which would be ripe for exploitation by smart lawyers if something like the report's proposals were adopted.

What seems to be needed is a wide ranging and extensive public discussion aimed at obtaining agreement about what sort of organisations pursuing what sort of purposes should be able to give tax deductibility to donors (and enjoy other tax concessions). This should be followed by an attempt to enshrine the agreement in statute and to redraft those sections of taxation law to reflect the modern world. The term 'charity' needs to be confined to the history books. But such a process would take years. In the meantime, an arrangement by which certain community organisations were given tax-deductible status by administrative procedure seems warranted. Similar 
arrangements exist for sporting, environment and arts organisations and could readily be adapted so as to resolve, at least temporarily, anomalies in the current tax treatment of community organisations.

\section{Conclusion}

The report covers many issues. It makes some sensible recommendations designed to encourage community organisations to provide services of the highest quality and reports a pioneering but ultimately unsuccessful attempt at benchmarking community organisations. Overall, if the majority of its recommendations were adopted, governments would have to change more than community organisations would. It is the first major government report into an important set of nonprofit organisations in Australia. It testifies to a belated recognition by government of their importance. Given growing international recognition of nonprofit organisations, it is unlikely to be the last.

\section{References}

Ben-Ner, A. \& B. Gui (eds) (1993), The Nonprofit Sector in the Mixed Economy, Ann Arbor, University of Michigan Press.

Industry Commission (IC) (1994), 'Inquiry into Charitable Organisations: Transcript of proceedings at Melbourne on Tuesday 19th July, 1994': 2997-8.

Inter-Secretariat Working Group on National Accounts (1993), System of National Accounts 1993, United Nations et al, New York.

Krever, R. (1991), 'Tax deductions for Charitable Donations: A Tax Expenditure Analysis', in R. Krever \& G. Kewley (eds), Charities and Philanthropic Organisations: Reforming the Tax Subsidy and Regulatory Regimes, Comparative Public Policy Research Unit, Monash University, and Australian Tax Research Foundation, Melbourne.

Lyons, M. (1993), Tax Deductibility of Donations to Community Welfare Organisations: A Report of a Survey, University of Technology, Sydney (CACOM Working Paper No. 17).

- (1994), 'Australia's Non-profit Sector', in S. Saxon-Harrold \& J. Kendall (eds), Reseanching the Vof untary Sector (2e), Charities Aid Foundation, London.

- (1995), 'The Development of Quasi-Vouchers in Australia's Community Services', Policy and Polktics 23(2) (forthcoming).

McGregor-Lowndes, M. (1994), A Taxing Definition-a Comment on the Industry Commission's Draft Proposal for Defining Community Social Welfare Organisations, Queensland University of Technology, Brisbane (Program on Nonprofit Corporations Working Paper No. 45).

Rose-Ackermann, S. (ed.) (1986), The Economics of Nonprofit Institutions: Studies in Structure and Policy, Oxford University Press, New York.

Salamon, L (1994), 'The Rise of the Nonprofit Sector', Foreign Affairs 73(4): 109-22.

Weisbrod, B. (1988), The Nonprofit Economy, Harvard University Press, Cambridge, Mass. 